\title{
Pain during arterio-venous fistula (AVF) cannulation
}

\author{
Béfa Noto Kadou Kaza ${ }^{1}$, Kossi Akomola Sabi ${ }^{2}$, Eyram Yoan Makafui Amekoudi ${ }^{2}$, \\ Ghislain Imangue ${ }^{1}$, Jacques Badibanga ${ }^{1}$, Claude Mawufemo Tsevi ${ }^{2}$, \\ Aminata Yasminatou Bikinga Wendkuuni ${ }^{1}$, Denis Georges Teuwafeu ${ }^{1}$, \\ Mohamed Gharbi Benghanem ${ }^{1}$, Benyounes Ramdani ${ }^{1}$ \\ ${ }^{1}$ Departement of Nephrology, Dialysis and Renal Transplantation of University Teaching Hospital Ibn Rochd of Casablanca, Morocco \\ ${ }^{2}$ Departement of Nephrology and Hemodialysis of University Teaching Hospital Sylvanus Olympio of Lomé, Togo
}

\section{Email address:}

bfanotokadoukaza@yahoo.fr (B. N. K. Kaza),kossi.sabi@gmail.com (K. A. Sabi)

\section{To cite this article:}

Béfa Noto Kadou Kaza, Kossi Akomola Sabi, Eyram Yoan Makafui Amekoudi, Ghislain Imangue, Jacques Badibanga, Claude Mawufemo Tsevi, Aminata Yasminatou Bikinga Wendkuuni, Denis Georges Teuwafeu, Mohamed Gharbi Benghanem, Benyounes Ramdani. Pain during Arterio-Venous Fistula (AVF) Cannulation. American Journal of Internal Medicine. Vol. 2, No. 5, 2014, pp. 87-89.

doi: 10.11648/j.ajim.20140205.12

\begin{abstract}
Pain caused by medical care is a major concern of patients. Patients undergoing hemodialysis are submitted to two venous punctures at rate of two or three times per week and this by means of big needles gauge. Where pain during ArterioVenous Fistula (AVF) cannulation should be the object of adequate take care. However few works are dedicated to it. Our purpose was to estimate prevalence, risk factors and take care of pain due to AVF cannulation to hemodialysis patients. It was monocenter study realized from 1st till 30 September 2013 in the unit of hemodialysis of University Teaching Hospital Ibn Rochd of Casablanca. It included 92 hemodialysis patients, who's carried AVF dating of at least three months and having agreed to participate that study. The investigation was realized by a doctor. The content of the tools used for investigation was established and validated by our department. Intensity of pain estimated by means of an analogue visual scale, was quoted from 0 to 10. The pain was estimated at every patient's during two consecutive hemodialysis sessions just after the bipunction of AVF by means of needles of 16 gauge by the same nurse. The mean age was 43,76 $\pm 13,6$ years with a parity of sex. Prevalence of pain was $60,9 \%$ with a moderate intensity expressed in $63 \%$ of cases. About $31,5 \%$ had apprehension of puncture. The anesthetic cream was the only method used for pain take care and its rate of use was 3,6\%. The risk factors of the pain were: proximal situation of $\operatorname{AVF}(p=0,020)$, apprehension of puncture $(p=0,037)$. In our hemodialysis center, pain during AVF cannulation remains a real problem both by its high prevalence and its lower take care. Where it imports to elaborate a strategy to manage this pain.
\end{abstract}

Keywords: Pain, Cannulation, Arterio-Venous Fistula, Hemodialysis

\section{Introduction}

Pain caused by medical care constitutes a major concern of the patients [1]. It's a permanent problem for patients undergoing hemodialysis. Indeed apart from chronic pains which are singularly due to minerals and bones disorders, Arterio-Venous Fistula (AVF) cannulation is another source of pain because of its repetition like act, two to three times per week, 300 approximately per year by means of big needles gauge. This contributes to decreased patients life quality. Where pain during AVF puncture should be the object of an adequate take care. However few works are dedicated to it. The purpose of our study was to estimate prevalence, risk factors and take care of pain due to AVF cannulation to our hemodialysis patients.

\section{Methodology}

It was single center prospective study realized from 1 st till 30 September 2013 in the unity of hemodialysis of University Teaching Hospital Ibn Rochd of Casablanca. It included 92 of the 103 hemodialysis that count our center, bearers of AVF dating of at least three months and having agreed to participate to study. Among those who were not included, 3 patients dialysed on central venous catheter, 3 patients carried AVF of less than three months, and 5 patients carried AVF of more than three months but having refused to 
participate to study. Investigation was realized by a doctor. The tools used for data collection were a questionnaire for collecting demographic and clinical data, a numerical rating scale for subjective pain assessment by Visual Analogue Score (VAS), risk factors and take care of the pain due to AVF cannulation. The content of the tools was established and validated by our department. Pain perception was recorded by patients immediately after cannulation on a VAS. It was estimated at every patient's during two consecutive hemodialysis sessions just after the bipunction of AVF by means of needles of 16 gauge by the same nurse. The quotation of the intensity using VAS was: 0 for absence of pain, low $=1-2$, moderated $=3-5$, severe $=6-8$, very severe $=9$ 10. Data analysis was done using SPSS 18.0; both descriptive and inferential statistics were used. Descriptive statistics used in the study were frequencies, percentage, mean median, range, and standard deviation. Chi square, two-sample and paired t-tests, the Mann Whitney test, for inferential statistics as deemed appropriate. $\mathrm{p}<0.05$ was considered as significant.

\section{Results}

Among 92 hemodialysis patients include in study, there was a parity of sex; the mean age was $43,76 \pm 13,6$ years. Prevailed nephropathy etiology was glomerulonephritis with $32,6 \%$. The duration of hemodialysis was of $156,99 \pm 74,3$ months ( Table1). There were 93,5\% native AVF. Distal AVF was dominant in $78,3 \%$. Duration of the AVF was of $103 \pm 70,3$ months ( Table2). Prevalence of the pain due to AVF puncture was $60,9 \%$. The mean of intensity was $2,53 \pm 2,6$ with an ascendancy of the shape moderated $(62 \%)$. Only $3,6 \%$ of patients who felt pain used the anesthetic cream (cream EMLA: Eutetic mixture of lidocaine and prilocaine in emulsion) before puncture with $100 \%$ efficiency. No other analgesic preventive method was practiced. Among the group of the patients without pain, nobody used the anesthetic cream. No other analgesic method was practiced (Table3). In univariate analysis, the proximal situation of the $\operatorname{AVF}(\mathrm{p}=0,020)$ and the apprehension before the puncture ( $p=0,037$ ) were significantly associated with the arisen of the pain during AVF cannulation(Table4). In multivariate analysis there was no risk factor.

Table 1. Demographic and clinical data of the 92 maintenance hemodialysis (HD) patients

\begin{tabular}{ll}
\hline & $\begin{array}{l}\text { Maintenance HD Patients } \\
(\mathbf{n}=\mathbf{9 2})\end{array}$ \\
\hline Age (mean \pm SD), Yr & $43,76 \pm 13,6$ \\
Females, n (\%) & $46(50)$ \\
Dialysis duration (mean \pm SD), months & $156,99 \pm 74,3$ \\
Nephropathy etiology, n(\%) & \\
Diabetic nephropathy & $3(3,3)$ \\
Glomerulonephritis & $30(32,6)$ \\
Unknown & $35(38)$ \\
Nephroangiosclerosis & $8(8,7)$ \\
Interstitial nephropathy & $16(17,4 \%)$ \\
\hline
\end{tabular}

Table 2. Caracteristics of AVF

\begin{tabular}{ll}
\hline & AVF $(\mathrm{n}=92)$ \\
\hline Type, $\mathrm{n}(\%)$ & \\
Native AVF & $86(93,5)$ \\
Prothetic AVF & $6(6,5)$ \\
Situation, $\mathrm{n}(\%)$ & \\
Distale & $72(78,3)$ \\
Proximal & $20(21,7)$ \\
Mean duration, (mean $\pm \mathrm{SD})$, months & $103,16 \pm 70,3$ \\
Surgical resumption, $\mathrm{n}(\%)$ & $44(47,8)$ \\
\hline
\end{tabular}

Table 3. Prevalence and take care data on AVF's pain

\begin{tabular}{ll}
\hline & AVF's pain $(\mathbf{n}=\mathbf{5 6})$ \\
\hline Prevalence, $\mathrm{n}(\%)$ & $56(60,9)$ \\
Intensity, $\mathrm{n}(\%)$ & \\
Low & $11(20)$ \\
Moderate & $35(62)$ \\
Severe & $8(14)$ \\
Very severe & $2(4)$ \\
Take care & \\
Use of anesthetic cream, $\mathrm{n}(\%)$ & $2(3,6)$ \\
\hline
\end{tabular}

Table 4. Risk factors of the pain of the AV (univariate analysis)

\begin{tabular}{|c|c|c|c|}
\hline & \multicolumn{2}{|l|}{ Pain } & \multirow{2}{*}{$P$ value } \\
\hline & No $=36(39,1)$ & Yes $=56(60,9)$ & \\
\hline Age (Yr) & $43,61 \pm 14,6$ & $43,86 \pm 13,1$ & 0,268 \\
\hline \multicolumn{4}{|l|}{$\operatorname{Sex}(\%)$} \\
\hline Males & 58 & 45 & \multirow[t]{2}{*}{0,143} \\
\hline Females & 42 & 55 & \\
\hline $\begin{array}{l}\text { Duration on dialysis } \\
\text { (months) }\end{array}$ & $156,94 \pm 14,6$ & $157,02 \pm 77,6$ & 0,690 \\
\hline \multicolumn{4}{|l|}{ Type of AVF (\%) } \\
\hline Native AVF & 94 & 93 & \multirow[t]{2}{*}{0,563} \\
\hline Prothetic AVF & 6 & 7 & \\
\hline \multicolumn{4}{|l|}{ Situation of AVF (\%) } \\
\hline Distale & 94 & 68 & \multirow[t]{2}{*}{0,020} \\
\hline Proximal & 6 & 32 & \\
\hline $\begin{array}{l}\text { Duration of AVF } \\
\text { (months) }\end{array}$ & $112,83 \pm 69,9$ & $96,95 \pm 67,9$ & 0,806 \\
\hline $\begin{array}{l}\text { Apprehension during } \\
\text { cannulation }(\%)\end{array}$ & 19 & 39 & 0,037 \\
\hline
\end{tabular}

\section{Discussion}

Arterio-Venous Fistula is one of the inevitable elements in the take care of hemodialysis patients. Quality of dialysis depends on its good functioning. So the different complications which result from its use like pain during cannulation influence directly life's quality of hemodialysis patients. Pain of AVF puncture is a real problem for patients. Indeed its prevalence is high in differents studies. Vergne and al in France [1], Gulperi and al in Turkey [2] had reported respectively $57,5 \%$ and $56,1 \%$ for the prevalence of pain which occurs during AVF puncture. In our study that rate was $60,9 \%$. Besides this high prevalence, the intensity of pain at our patients was not negligible. It was dominated by the shape moderated $(62 \%)$, this in spite of so long duration of hemodialysis. However it's take care remains almost nonexistent. Indeed only 3,6 \% of these prevailed patients used an analgesic preventive method. It was exclusively about some anesthetic cream. This using of anesthetic cream is unimportant compared with Vergne and al study in which 
$(60,5 \%)[1]$. The weak rate of anesthetic cream using in our study could be partially connected to its weak accessibility as well in terms of cost as availability in pharmacy. Using of anesthetic cream is the only method used by our patients to prevent pain occurs during AVF cannulation. Nevertheless, it exist many others pharmacological and none pharmacological means of AVF cannulation's pain take care. In the series of the pharmacological methods, we could quote local injection of an anesthetic such as the lidocaine, the custom of the local analgesic in spray on base of the éthylchloride. Local anesthetic injection is not usually used because of vasoconstriction, pain and infections that occur [2]. The use of analgesic in spray is easier for patients than anesthetic cream which would require many more precautions of custom to be effective $[3,4]$. None pharmacological means have the advantage to be less expensive compared with pharmacological one, and consequently to be more accessible for our patients. The methods of cutaneous stimulation by massage or by cold were experimented with efficiency in numerous studies [5-8]. The stimulation by cold or cryotherapy consists of applying ice cubes to the previous face of 5 fingers of contralateral hand of AVF during puncture [8]. Distraction method which consists to amuse patient during puncture was tried with efficiency at children and teenagers [9]. Buttonhole method is the most spread and best method studied among all none pharmacological methods [10-14]. It consists simply in the re-use of the same points of cannulation in every session of hemodialysis. It is effective in terms of reduction of pain, but also prolongs the survival of AVF. So certain complications of AVF such as aneurysm and hematoma are decreased by this method. However infectious complications seem more frequent with this method which requires of advantage of asepsis. Aromatherapy is a more recent technique which was experimented to 92 hemodialysis patients in 2013 by BagheriNesami and al in Iran in randomized and controlled study [15]. It consisted to make inhale to patients of experimental group, an essence of lavender (10\% of concentration) during 5 times before hemodialysis session and, this during 3 consecutive sessions of hemodialysis. It allowed to reduce significantly pain occurs during AVF cannulation.

In our study, AVF cannulation's pain was significantly associated to the proximal situation of AVF and to the apprehension. Other risk factors such as advanced age, female gender, and mean duration of AVF have been reported in others studies [1, 8]. Apprehension management during puncture allowed certain authors to reduce significantly prevalence and intensity of the AVF's pain [9]. Our study is limited by the subjective method used to evaluate pain intensity.

\section{Conclusion}

Pain due to AVF cannulation remains a major problem for our patients. It is important to set up a program of prevention suited for our patients and which will be especially based on the use of the not pharmacological means.

\section{Interest Conflicts}

On behalf of all authors, the corresponding author states that there is no conflict of interest.

\section{References}

[1] H. Vergne , MC. Darnis, A. Ostertag, JM. Poux. Pain during arterio-venous puncture. www.cnrd.fr

[2] C. Gülperi, O. Orhan, Y. Mümtaz, D. Ipek, O. Seda, A. Seza. Vapocoolant Spray vs Lidocaine/Prilocaine Cream for Reducing the Pain of Venipuncture in Hemodialysis Patients. Int J Med Sci. 2011; 8(7): 623-627.

[3] LK. Bal. Improving arteriovenous fistula cannulation skills. Nephrol Nursing Jr 2005; 32:6.

[4] IR. Selby, BJ Bowles. Analgesia for venous cannulation: a comparison of EMLA (5 minutes of application), lignocaine, ethyl chloride, and nothing. J R Soc Med. 1995; 88: 264-267.

[5] P. Armstrong, C. Young, D. McKeown. Ethyl chloride and venous puncture pain: a comparison with intradermal lidocaine. Can J Anaesth. 1990; 37: 656-658.

[6] JS. Park. The effect of cutaneous stimulation on AV fistula punctures pain of hemodialysis patients. Taehan Kanho 1994; $33: 37-51$.

[7] JS. Park. The effect of cutaneous stimulation and distraction on IV injection pain of chemotherapy patients. J Korean Acad Nurs 1998; 28:303-18.

[8] PB. Sabitha, D. C. Khakha, S. Mahajan, S. Gupta, M. Agarwal, S. L. Yadav. Effect of cryotherapy on arteriovenous fistula puncture-related pain in hemodialysis patients. Indian Journal of Nephrology October 2008 / Vol 18 / Issue 4:155-58.

[9] F. Alhani. The effect of programmed distraction on the pain caused by venipuncture among adolescents on hemodialysis. Pain Manag Nurs. 2010 Jun;11(2).

[10] LK. Ball: The buttonhole technique for arteriovenous fistula cannulation. Nephrol Nurs J 33: 299-304, 2006.

[11] AM. Verhallen, MP. Kooistra, BC. van Jaarsveld: Cannulating in haemodialysis: Rope-ladder or buttonhole technique? Nephrol Dial Transplant 22:2601-2604, 2007

[12] E. Vaux, J. King, S. Lloyd, J. Moore, L. Bailey, I. Reading, R. Naik. Effect of buttonhole cannulation with a polycarbonate PEG on in-center hemodialysis fistula outcomes: a randomized controlled trial. Am J Kidney Dis. 2013 Jul;62(1):81-8.

[13] CA. Muir, SS. Kotwal , CM. Hawley, K. Polkinghorne, MP. Gallagher, P. Snelling, MJ. Jardine. Buttonhole cannulation and clinical outcomes in a home hemodialysis cohort and systematic review. Clin J Am Soc Nephrol. 2014 Jan;9(1):110-9.

[14] RK. Atkar, JM. MacRae. The buttonhole technique for fistula cannulation: pros and cons. Curr Opin Nephrol Hypertens. 2013 Nov;22(6):629-36.

[15] M. Bagheri-Nesami, F. Espahbodi, A. Nikkhah, SA. Shorofi, JY. Charati. The effects of lavender aromatherapy on pain following needle insertion into a fistula in hemodialysis patients 